\title{
Adenovirus-mediated chronic "hyper-resistinemia" leads to in vivo insulin resistance in normal rats
}

\author{
Hiroaki Satoh, ${ }^{1}$ M.T. Audrey Nguyen,, ${ }^{1}$ Philip D.G. Miles, ${ }^{2}$ Takeshi Imamura, ${ }^{1}$ Isao Usui, ${ }^{1}$ \\ and Jerrold M. Olefsky1,3,4 \\ 1Department of Medicine, Division of Endocrinology and Metabolism, University of California, San Diego, La Jolla, California, USA. \\ 2Department of Surgery, University of California, San Diego, San Diego, California, USA. ${ }^{3}$ The San Diego Veterans Affairs Medical Center, \\ La Jolla, California, USA. ${ }^{4}$ Larry L. Hillblom Foundation, La Jolla, California, USA.
}

\begin{abstract}
We investigated the chronic in vivo effect of resistin on insulin sensitivity and glucose metabolism by overexpressing resistin protein in male Wistar rats using intravenous administration of an adenovirus encoding mouse resistin. After 7 days of elevated resistin levels at a supraphysiological concentration, the animals displayed glucose intolerance and hyperinsulinemia during glucose tolerance tests, and insulin tolerance tests demonstrated an impaired glucose-lowering effect of insulin. The glucose clamp studies were performed at submaximal $(4 \mathrm{mU} / \mathrm{kg} / \mathrm{min})$ and maximal $(25 \mathrm{mU} / \mathrm{kg} / \mathrm{min})$ insulin infusion rates and demonstrated the presence of insulin resistance induced by elevated resistin levels. Indeed, the insulin-stimulated glucose infusion rate was decreased by $12-31 \%$; suppression of hepatic glucose output was attenuated by $28-55 \%$; and insulin suppression of circulating FFA levels was inhibited by $7 \%$. Insulin receptor substrate- 1 and -2 phosphorylation and Akt activation were impaired in muscle and adipose tissue. Interestingly, activation of AMP-activated protein kinase in skeletal muscle, liver, and adipose tissue was also significantly downregulated. Together, these results indicate that chronic "hyper-resistinemia" leads to whole-body insulin resistance involving impaired insulin signaling in skeletal muscle, liver, and adipose tissue, resulting in glucose intolerance, hyperinsulinemia, and hypertriglyceridemia. Thus elevated resistin levels in normal rats fed a regular chow diet produce many of the features of human syndrome $X$.
\end{abstract}

\section{Introduction}

Insulin resistance is a characteristic feature of syndrome $\mathrm{X}$ and type 2 diabetes mellitus and can be defined as a decreased ability of target tissues such as fat, liver, and skeletal muscle to respond normally to insulin. Skeletal muscle is the most important site of insulin-mediated glucose disposal, and in insulin-resistant states, insulin stimulation fails to adequately enhance glucose uptake (1-3). In the liver, insulin-induced suppression of hepatic glucose output (HGO) is attenuated, whereas in adipose tissue, impaired suppression of lipolysis results in elevated circulating FFA levels. In recent years, it has been demonstrated that cross-talk exists between these three insulin-responsive tissues, a process that integrates the insulin stimulus and coordinates the overall in vivo response. It has been proposed that adipocytokines like TNF- $\alpha$ (4), leptin (5), and adiponectin (also known as ACRP30, AdipoQ, apM1, and GBP28) (6-8), which are adipocyte-derived, biologically active peptide molecules, can help coordinate these multitissue metabolic events.

Recently, a new adipocytokine called "resistin" has been identified. Resistin is a member of a newly discovered, small family of cysteinerich secretory proteins $(9,10)$. It is expressed only in adipose tissue and is markedly induced during the differentiation of 3T3-L1 cells

Nonstandard abbreviations used: adenovirus (Adv); alanine aminotransferase (ALT); AMP-activated protein kinase (AMPK); aspartate aminotransferase (AST); glucose disposal rate (GDR); glucose tolerance test (GTT); hepatic glucose output (HGO); insulin receptor (IR); insulin receptor substrate (IRS); insulin tolerance test (ITT); thiazolidinedione (TZD); triglyceride (TG).

Conflict of interest: The authors have declared that no conflict of interest exists.

Citation for this article: J. Clin. Invest. 114:224-231 (2004)

doi:10.1172/JCI200420785 to mature adipocytes (9). Initial studies in rodents suggested that resistin is upregulated in both genetic and diet-induced obesity and is downregulated by thiazolidinediones (TZDs) (9). Resistin administration also impaired glucose tolerance, whereas immunoneutralization of this protein improved insulin action (9). Hence, this molecule has been proposed as a link between obesity and insulin resistance. Subsequently, however, conflicting experimental results regarding the role of resistin in obesity-induced insulin resistance have been reported. Several studies failed to confirm the original hypothesis and demonstrated reduced resistin expression in adipose tissue of obese mice and increased levels in leptin deficient $o b / o b$ mice and Zucker diabetic fatty rats in response to TZDs (11). Moreover, in human adipose tissue, resistin is detectable only at low levels, and a relationship between resistin and obesity has not been established $(12,13)$. Recently, acute infusion of adipose tissue-derived resistin and gut-derived resistin-like molecule- $\beta$ has been shown to markedly and rapidly induce hepatic insulin resistance in vivo (14), and in vitro treatment of cultured muscle cells with resistin inhibits glucose uptake (15). These studies raise the possibility that resistin is a modulator of overall insulin sensitivity. However, the physiological role of resistin and its chronic in vivo effects are still unknown.

To investigate the role of resistin in insulin and glucose metabolism, we used an adenovirus (Adv) to chronically overexpress resistin in male Wistar rats. Our results show that chronic "hyper-resistinemia" induced by Adv-mediated gene transfer leads to insulin resistance in skeletal muscle, liver, and adipose tissue, resulting in glucose intolerance, hyperinsulinemia, and hypertriglyceridemia, thus mimicking many of the features of the metabolic syndrome or syndrome X. 


\section{Methods}

Subcloning of the mouse resistin gene by RT-PCR. Total RNA was extracted from differentiated 3T3-L1 adipocytes using TRIzol reagent (Invitrogen, Carlsbad, California, USA). Briefly, $1 \mu \mathrm{g}$ of total RNA was reverse-transcribed with 200 units of reverse transcriptase using the Superscript II kit (Invitrogen) according to the manufacturer's recommendations. Mouse resistin cDNA (359 bp) was amplified using 5'-GTACCCACGGGATGAAGAACC-3' sense and $5^{\prime}$-ACATCAGGAAGCCTGCAG-3' antisense primers. PCR products were separated on a $2 \%$ agarose gel and purified using the QIAquick PCR Purification Kit (QIAGEN, Valencia, California, USA). The mouse resistin cDNA was thereafter subcloned into the pCR2.1-TOPO (Invitrogen) and sequenced, confirming that the clones corresponded to the mouse resistin (GenBank accession number AF323080).

Construction of recombinant Adv's. Mouse resistin cDNA was inserted in the pAxCAwt plasmid (TAKARA Biomedical, Shiga, Japan) to generate $\mathrm{pAxCAwt-mouse}$ resistin. The resulting plasmid, which contains the resistin cDNA under the control of a CAG promoter (CMV enhancer, chicken $\beta$-actin promoter, and part of an untranslated region of rabbit $\beta$-globin), was transfected into 293 cells. Recombinant Adv from a single plaque was expanded and purified twice by cesium chloride gradient ultracentrifugation. Viral titer was determined by plaque assay. Control Adv-lacZ, which carries $\beta$-gal cDNA, was isolated using the same procedure. Both recombinant viruses were dialyzed in $\mathrm{PBS}, \mathrm{pH} 7.4$, and were stored in a solution of $10 \%$ glycerol in PBS at $-80^{\circ} \mathrm{C}$ until use.

Animal studies. Eight-week-old male Wistar rats (Harlan, Indianapolis, Indiana, USA) weighing about $300 \mathrm{~g}$ were housed individually in controlled light/dark (12 hour/12 hour) and temperature conditions and had free access to water and standard rat chow. They were injected intravenously in the tail with $1 \times 10^{9} \mathrm{PFU}$ of Adv-resistin or $A d v-l a c Z$ virus per rat. All procedures were performed in accordance with the Guide for Care and Use of Laboratory Animals of the NIH and were approved by the Animal Subjects Committee of the University of California, San Diego (San Diego, California, USA).

Glucose and insulin tolerance tests and euglycemic-byperinsulinemic clamp procedures. Rats were implanted with three catheters (MicroRenathane MRE-033; $0.033 \mathrm{~cm}$, outer diameter, and $0.014 \mathrm{~cm}$, inner diameter; Braintree Scientific, Braintree, Massachusetts, USA) on day 3 after the Adv injection. Two catheters were placed into the right jugular vein and another one was placed into the left carotid artery in rats sedated by single-dose anesthesia that consisted of $50 \mathrm{mg} / \mathrm{kg}$ ketamine $\mathrm{HCl}$ (Aveco, Fort Dodge, Indiana, USA), $4.8 \mathrm{mg} / \mathrm{kg}$ xylazine (Aveco), and $1 \mathrm{mg} / \mathrm{kg}$ acepromazine maleate (Sigma-Aldrich, St. Louis, Missouri, USA) given intramuscularly. Catheters were "tunneled" subcutaneously, exteriorized at the back of neck, and filled with heparinized saline. The jugular and carotid catheters were used for infusion and blood sampling, respectively.

On day 7 after the Adv injection, insulin sensitivity was assessed using a glucose tolerance test (GTT), insulin tolerance test (ITT), or euglycemic-hyperinsulinemic clamp. Rats underwent a 6-hour fast before the start of all experiments. For the GTT, rats were injected with $2 \mathrm{~g}$ dextrose/ $\mathrm{kg}$ body weight (50\% dextrose; Abbott, Chicago, Illinois, USA) in the jugular vein. Blood samples were collected from the carotid artery at $0,15,30,60,90$, and 120 minutes. For the ITT, the rats were injected with $0.75 \mathrm{U}$ human insulin $/ \mathrm{kg}$ body weight (Novolin R; Novo Nordisk, Copenhagen, Denmark). Blood samples were collected after $0,15,30$, and 60 minutes.
The euglycemic-hyperinsulinemic clamp experiments began with a priming injection $(2.5 \mu \mathrm{Ci} / 0.5 \mathrm{ml})$ and constant infusion $(0.04$ $\mu \mathrm{Ci} / \mathrm{min}$ ) of D-[3- $\left.{ }^{3} \mathrm{H}\right]$-glucose (New England Nuclear, Boston, Massachusetts, USA). After 60 minutes of tracer equilibration and basal sampling at time 0 , glucose (50\% dextrose, variable infusion; Abbott, Chicago, Illinois, USA) and tracer plus insulin (4 or $25 \mathrm{mU} / \mathrm{kg} / \mathrm{min}$, Novolin R; Novo Nordisk) were infused into the jugular vein.

Small blood samples $(60 \mu \mathrm{l})$ were drawn at 10-minute intervals and were analyzed immediately for glucose content (YSI $2300 \mathrm{Glu-}$ cose Analyzer; Yellow Springs Instruments, Yellow Springs, Ohio, USA) to maintain the integrity of the glucose clamp throughout the duration of the experiment. Large blood samples $(250 \mu \mathrm{l})$ were obtained 60 minutes before and 0 minutes and 120 minutes after beginning glucose and tracer infusion, for determination of glucose-specific activity and insulin, FFA, and resistin content. We determined that steady-state conditions were achieved at the end of the clamp before obtaining the final blood specimen by measuring glucose values every 10 minutes and ensuring that a steady state for glucose infusion and plasma glucose levels was maintained for a minimum of 20 minutes before final sampling. We define a steady-state blood glucose concentration as a change of $3 \mathrm{mg} / \mathrm{dl}$ or less in 10 minutes and a change of glucose infusion rate of less than $5 \%$ in 10 minutes. All blood samples were centrifuged immediately and plasma was stored at $-80^{\circ} \mathrm{C}$ for subsequent analysis. After final blood sampling at 120 minutes, animals were promptly euthanized with pentobarbital $(180 \mathrm{mg} / \mathrm{kg})$. Tissues were obtained and then frozen immediately in liquid nitrogen and were stored at $-80^{\circ} \mathrm{C}$ for subsequent metabolic analysis.

Localization of recombinant gene expression. Histochemistry was done with X-gal. Cryostat sections were fixed for 10 minutes in $0.5 \%$ glutaraldehyde in PBS, rinsed twice for 10 minutes, each rinse in a solution of $1 \mathrm{mM} \mathrm{MgCl}$ in PBS, and stained overnight in a PBS solution containing $1 \mathrm{mg} / \mathrm{ml} \mathrm{X-gal,} 5 \mathrm{mM} \mathrm{K}_{3} \mathrm{Fe}(\mathrm{CN})_{6}, 5 \mathrm{mM}$ $\mathrm{K}_{4} \mathrm{Fe}(\mathrm{CN})_{6}$, and $1 \mathrm{mM} \mathrm{MgCl}_{2}$.

Analytical procedures. Plasma glucose was assayed by the glucose oxidase method (Yellow Springs Instruments). Basal plasma insulin was quantified using a rat insulin ELISA kit (CRYSTAL CHEM Inc., Chicago, Illinois, USA), and insulin values during the clamp studies were measured with a human-specific insulin RIA kit (Linco Research Inc., St. Charles, Missouri, USA). Plasma glucose-specific activity was measured in duplicate after zinc sulfate and barium hydroxide deproteinization. Plasma FFA, triglyceride (TG), leptin, resistin, and adiponectin levels were determined using the NEFA C-test, TG test (Wako Pure Chemical Industries, Richmond, Virginia, USA), Correlate-EIA rat Leptin Immunoassay Kit (Assay Designs Inc., Ann Arbor, Michigan, USA), Mouse Resistin RIA Kit (Linco Research Inc.), which cross-reacts with mouse and rat resistin, and Mouse/Rat Adiponectin ELISA kit (B-Bridge International Inc., San Jose, California, USA), respectively. Serum alanine aminotransferase (ALT) and aspartate aminotransferase (AST) levels were measured enzymatically with a commercial kit (Sigma-Aldrich).

Red quadriceps muscle, liver, and epididymal adipose tissue were homogenized in liquid nitrogen and lysed in buffer containing phosphatase and protease inhibitors. After a 10 -minute incubation, the lysates were clarified by centrifugation $(10,000 \mathrm{~g}$ at $4^{\circ} \mathrm{C}$ ) and quantified for total protein. Samples were separated by SDS-PAGE on $7.5 \%$ or $10 \%$ polyacrylamide gels. Proteins were transferred onto PVDF membranes (Immobilon-P; Millipore, Bedford, Massachusetts, USA) and blotted with antibodies against Akt1/2, phosphorylated Akt (Ser473 and Thr308), AMP-activat- 


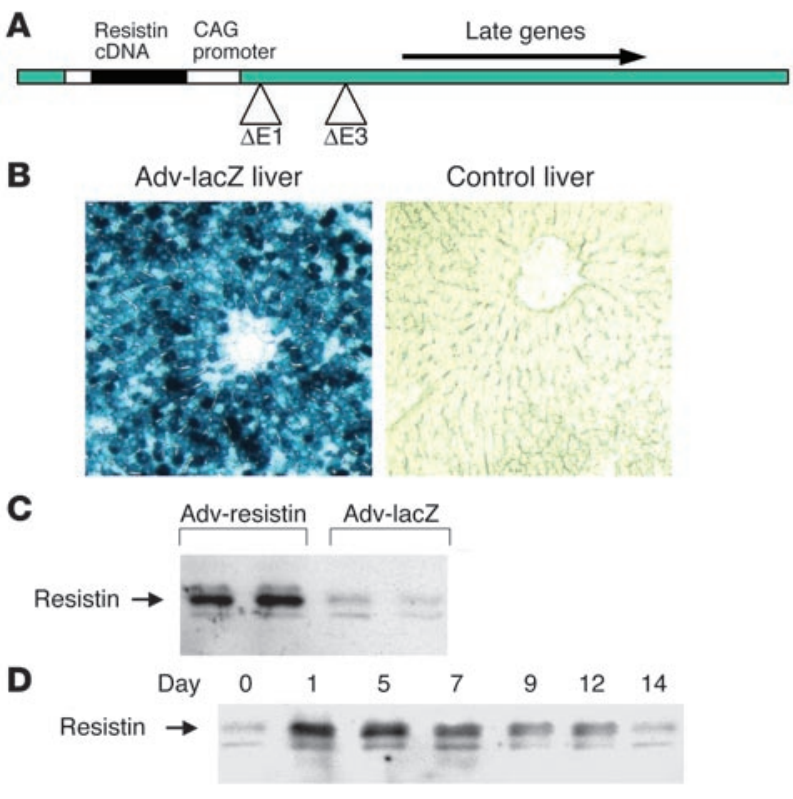

ed protein kinase- $\alpha$ (AMPK- $\alpha$ ), and phosphorylated AMPK- $\alpha$ (Thr172). Membranes were then incubated with HRP-conjugated secondary $\mathrm{Ab}$ prior to chemiluminescence detection (Pierce, Rockford, Illinois, USA).

For improved quality of insulin receptor (IR) signals, insulin receptor substrate-1 (IRS-1), and IRS-2, these proteins were immunoprecipitated from lysates using anti-IRS-1, anti-IRS-2 (Upstate Biotechnology), or anti-IR $\beta$ (Santa Cruz Biotechnology, Santa Cruz, California, USA) and protein A-agarose (Upstate Biotechnology). Eluates were subsequently treated as described above and blotted with monoclonal anti-phosphotyrosine (PY-20; Transduction Laboratories; Lexington, Kentucky, USA), anti-IRS-1, anti-IRS-2, and anti-IR and were detected as described above.

Plasma resistin levels were quantified by Western blot analysis. One microliter of plasma was subjected to $15 \%$ SDS-PAGE, transferred, blotted with resistin Ab (Affinity BioRegents, Golden, Colorado, USA), and detected as described above. Band intensities were quantified by densitometry using NIH Image 1.6 software.

Calculations. HGO and glucose disposal rate (GDR) were calculated for the basal period and steady-state portion of the glucose clamp procedure using the Steele equation for steady-state conditions (16). Data calculation and statistical analysis were performed using the StatView program (Abacus Concepts Inc., Berkeley, California, USA). Data are presented as mean \pm SEM. Statistical significance was tested with repeated-measures using ANOVA. Statistical significance was defined as a $P$ value of less than 0.05 .

\section{Results}

Plasma resistin levels. To study the chronic effects of resistin in vivo, we overexpressed the resistin protein by injecting male Wistar rats with Adv-resistin or control Adv-lacZ. To accomplish this, we constructed a replication-defective Adv expressing the mouse resistin cDNA from the CAG promoter (Figure $1 \mathrm{~A}$ ). Previous studies have shown that intravenously administrated Adv's are targeted to the liver, with more than $90 \%$ of hepatocytes expressing virus-encoded proteins $(17,18)$, and this was confirmed by lacZ staining of liver sections (Figure 1B).

\section{Figure 1}

Adenoviral transduction of mouse resistin expression. (A) Structure of Adv encoding mouse resistin. E1 and E3 indicate deletion of early genes 1 and 3 . Arrows indicate direction of gene transcription in the construct. (B) Analysis of Adv-infected rat liver for lacZ expression. Rats were injected with Adv-lacZ and euthanized on day 7 after injection, and liver tissue was evaluated for lacZ expression with the X-gal histochemical stain (left panel). Control liver did not stain with X-gal (right panel). (C and D) Western blot analysis of plasma resistin protein levels in male Wistar rats injected with Adv-resistin. (C) Plasma resistin protein level on day 7 after Adv injection. (D) Representative time course of the appearance and disappearance of resistin of adenoviral origin in the plasma of rats injected with Adv-resistin. Plasma samples were collected on the indicated day after injection (above lanes). After separation of $1 \mu \mathrm{l}$ of the plasma samples by SDS-PAGE, proteins were transferred to PVDF membrane, and resistin was detected using a polyclonal $\mathrm{Ab}$ against mouse resistin.

To confirm the high level of resistin protein expression in vivo, we performed Western blotting of plasma samples obtained on day 7 after injection. The in vivo expression of resistin was 5- to 10-fold higher in rats injected with Adv-resistin than in controls injected with Adv-lacZ, as demonstrated in Figure 1C, and this was confirmed by RIA measurements of resistin levels (data not shown). Thus, liver cells infected with Adv-resistin secreted high levels of resistin into the circulation, reaching supraphysiological levels.

To determine the duration of expression of resistin protein, we performed Western blotting of plasma samples collected at multiple time points after Adv injection and Figure 1D shows the time course of resistin content in the plasma of rats injected with Adv-resistin. Plasma levels increased fairly rapidly on day 1 , were sustained at a high level to day 7 and declined gradually from day 7 to day 14 . We therefore conducted all subsequent in vivo experiments on day 7 after injection.

Overall animal characteristics. Table 1 illustrates some of the general characteristics of the rats injected with Adv-resistin and control Adv-lacZ in the basal state and on day 7 after injection. Liver

\section{Table 1}

Body weight and basal plasma measurements in rats injected with Adv-resistin versus control Adv-lacZ

\begin{tabular}{lcc} 
& Adv-lacZ (control) $(\boldsymbol{n})$ & Adv-resistin $(\boldsymbol{n})$ \\
Body weight $(\mathrm{g})$ & $292.2 \pm 4.8(17)$ & $295.4 \pm 7.4(17)$ \\
Liver function & & \\
$\quad$ AST $(\mathrm{IU})$ & $35.4 \pm 1.5(17)$ & $37.4 \pm 2.1(17)$ \\
$\quad$ ALT $(\mathrm{IU})$ & $38.2 \pm 1.3(17)$ & $39.1 \pm 1.6(17)$ \\
Glucose $(\mathrm{mg} / \mathrm{dl})$ & $129.7 \pm 3.5(17)$ & $125.6 \pm 5.0(17)$ \\
Insulin $(\mathrm{ng} / \mathrm{ml})$ & $0.73 \pm 0.05(17)$ & $1.26 \pm 0.08^{\mathrm{A}}(17)$ \\
TG $(\mathrm{mg} / \mathrm{ml})$ & $63.5 \pm 2.1(17)$ & $79.4 \pm 2.6^{\mathrm{A}}(17)$ \\
FFA $(\mathrm{mM})$ & $1.09 \pm 0.14(17)$ & $1.42 \pm 0.16^{\mathrm{A}}(17)$ \\
Leptin $(\mathrm{ng} / \mathrm{ml})$ & $7.74 \pm 3.12(17)$ & $7.03 \pm 2.56(17)$ \\
Adiponectin $(\mu \mathrm{g} / \mathrm{ml})$ & $8.66 \pm 1.19(17)$ & $7.94 \pm 2.30(17)$ \\
\hline
\end{tabular}

${ }^{A} P<0.05$. 

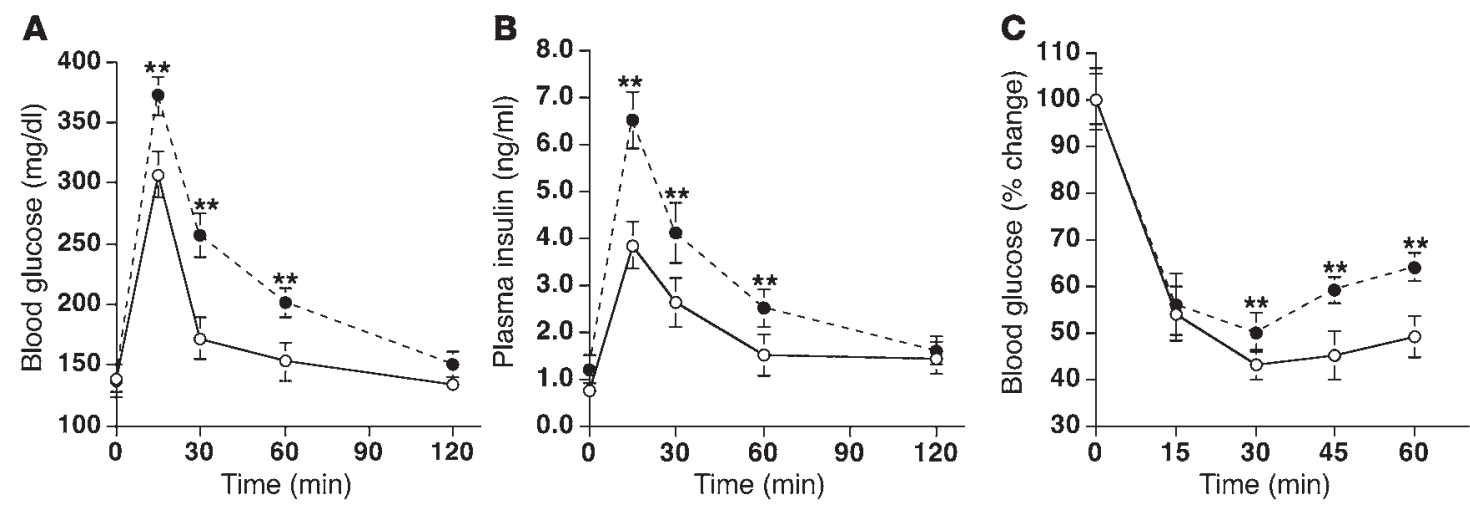

Figure 2

Hyper-resistinemia impairs glucose tolerance. GTT (A and B) and ITT (C) in male Wistar rats on day 7 after Adv injection. Glucose (A) and insulin (B) concentrations from the GTTs of rats injected with Adv-lacZ (open circles; $n=8$ ) or Adv-resistin (filled circles; $n=8$ ) that were then injected with $2 \mathrm{~g}$ glucose/kg body weight after a 6-hour fast. (C) Glucose curves for the ITTs of rats injected with Adv-lacZ (open circles; $n=8$ ) or Adv-resistin (filled circles; $n=8$ ) that were then injected with $0.75 \mathrm{U}$ human insulin $/ \mathrm{kg}$ body weight after a 6 -hour fast. Plasma glucose levels were normalized to those at 0 minutes in each group (100\%). ${ }^{\star \star} P<0.05$.

function was normal in both groups, with AST and ALT values within the normal range, indicating an absence of toxicity induced by Adv injection. Body weights and food intake (data not shown) were not different between the Adv-resistin and control Adv-lacZ groups (Adv-resistin, $295.4 \pm 7.4$ g; Adv-lacZ, $292.2 \pm 4.8$ g; Table 1). In the fasting state, glucose, leptin, and adiponectin levels were the same for the two groups, whereas rats injected with Adv-resistin were hyperinsulinemic (Adv-resistin, $1.26 \pm 0.08 \mathrm{ng} / \mathrm{ml}$; Adv-lacZ, $0.73 \pm 0.05 \mathrm{ng} / \mathrm{ml} ; P<0.05)$ and hyperlipidemic, with elevated TG levels (Adv-resistin, $79.4 \pm 2.6 \mathrm{mg} / \mathrm{ml}$; Adv-lacZ, $63.5 \pm 2.1 \mathrm{mg} / \mathrm{ml}$; $P<0.05)$ and FFA levels (Adv-resistin, $1.42 \pm 0.16 \mathrm{mM}$; Adv-lacZ, $1.09 \pm 0.14 \mathrm{mM} ; P<0.05)$.

Glucose and insulin tolerance tests. On day 7 after Adv injection, GTTs were performed on rats that had fasted for 6 hours and had received injection of $2 \mathrm{~g}$ glucose $/ \mathrm{kg}$ body weight into the jugular vein. As seen in Figure 2A, the fasting glucose levels showed no significant difference between the Adv-lac Z and Adv-resistin groups. However, after the glucose load the blood glucose levels were significantly elevated in the rats injected with Adv-resistin ( 50\%) after 15, 30, and 60 minutes $(P<0.05)$. Fasting insulin levels were also significantly higher $(-50 \%)$ in rats injected with Adv-resistin, as were plasma insulin levels after the glucose load (Figure $2 \mathrm{~B} ; P<0.05$ ), suggesting the development of insulin resistance after 7 days of hyper-resistinemia.

ITTs ( $0.75 \mathrm{U}$ insulin $/ \mathrm{kg}$ of body weight) performed on rats that had fasted for 6 hours were consistent with the occurrence of overall decreased insulin sensitivity. The glucose-lowering effect of insulin was significantly impaired in rats injected with Adv-resistin compared with controls injected with Adv-lacZ $(P<0.05)$.

Euglycemic-byperinsulinemic clamps. To directly examine the quantitative effect of resistin overexpression on insulin sensitivity, we next subjected both groups of rats to euglycemic-hyperinsulinemic clamping. These experiments were performed on day 7 after injection at both maximal $(25 \mathrm{mU} / \mathrm{kg} / \mathrm{min})$ and submaximal $(4 \mathrm{mU} /$ $\mathrm{kg} / \mathrm{min}$ ) insulin infusion rates. Steady-state glucose and insulin levels during the clamp studies were the same in the two groups, as shown in Table 2. As seen in Figure 3, the glucose infusion rate required to maintain euglycemia was decreased by $15 \%$ at maximal insulin stimulation and by $31 \%$ at submaximal insulin stimulation in rats injected with Adv-resistin.
Basal HGO values showed no difference between rats injected with Adv-resistin and those injected with Adv-lacZ (15.3 \pm 1.8 $\mathrm{mg} / \mathrm{kg} / \mathrm{min}$ and $15.2 \pm 1.4 \mathrm{mg} / \mathrm{kg} / \mathrm{min}$, respectively). During the clamp studies, the inhibition of $\mathrm{HGO}$ by insulin was attenuated in the Adv-resistin group. Insulin decreased HGO to $3.8 \pm 0.5 \mathrm{mg} /$ $\mathrm{kg} / \mathrm{min}$ in rats injected with Adv-lacZ at maximal insulin stimulation, but to only $5.8 \pm 0.3 \mathrm{mg} / \mathrm{kg} / \mathrm{min}$ in rats injected with Advresistin; at submaximal insulin stimulation, insulin suppressed HGO to $7.9 \pm 1.4 \mathrm{mg} / \mathrm{kg} / \mathrm{min}$ and $10.1 \pm 0.8 \mathrm{mg} / \mathrm{kg} / \mathrm{min}$ in rats injected with control Adv-lacZ and those injected with Adv-resistin, respectively $(P<0.01)$ (data not shown).

Plasma FFA levels in the basal state and during the englycemicbyperinsulinemic clamp studies. To assess whether resistin overexpression also affected adipose tissue insulin sensitivity, we measured plasma FFA levels (Figure 4A). In the basal state, plasma FFA levels were significantly higher $(P<0.05)$ in the rats injected with Adv-resistin than in controls (1.42 $\pm 0.16 \mathrm{mM}$ and $1.09 \pm 0.14 \mathrm{mM}$, respectively). At submaximal insulin stimulation, insulin suppressed FFA levels to $0.38 \pm 0.06 \mathrm{mM}$ in the control animals compared with $0.60 \pm 0.08 \mathrm{mM}$ in the Adv-resistin group $(P<0.05)$. At maximal insulin stimulation, FFA levels were sup-

\section{Table 2}

Plasma glucose and insulin levels during euglycemichyperinsulinemic clamping studies

$\begin{array}{lcc}\begin{array}{l}\text { Arterial glucose }(\mathrm{mg} / \mathrm{dl}) \\ \text { Maximal insulin } \\ \text { stimulation }\end{array} & 151.1 \pm 0.6(10) & 151.0 \pm 1.1(10) \\ \begin{array}{l}\text { Submaximal insulin } \\ \text { stimulation }\end{array} & 150.3 \pm 1.6(7) & 150.5 \pm 0.9(7) \\ \begin{array}{l}\text { Arterial insulin (pmol/l) } \\ \text { Maximal insulin } \\ \text { stimulation }\end{array} & 4,248 \pm 322(5) & 4,317 \pm 126(5) \\ \begin{array}{l}\text { Submaximal insulin } \\ \text { stimulation }\end{array} & 601 \pm 30(5) & 607 \pm 27(5)\end{array}$




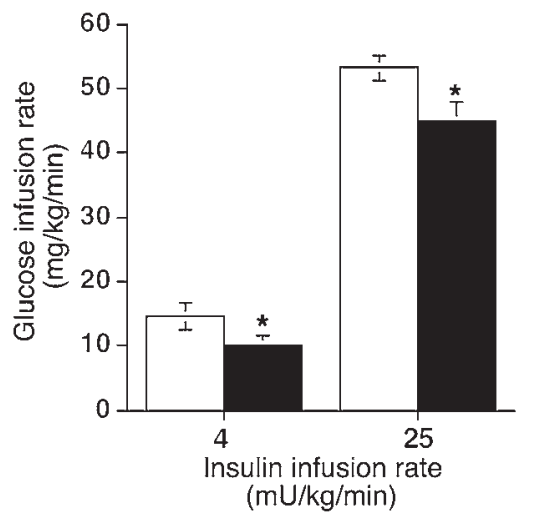

Figure 3

Glucose infusion rate during euglycemic-hyperinsulinemic clamping studies on day 7 after Adv injection. Data represent the glucose infusion rate required to maintain euglycemia during the hyperinsulinemic clamping study at infusion rates of 4 and $25 \mathrm{mU} / \mathrm{kg} / \mathrm{min}$ in rats injected with Adv-lacZ (white bars; $n=7$ and 10, respectively) or Adv-resistin (black bars; $n=7$ and 10, respectively). Values are means \pm SEM of data obtained from the analysis of rats injected with Adv-lacZ or Advresistin. ${ }^{*} P<0.01$

pressed to $0.09 \pm 0.02 \mathrm{mM}$ versus $0.22 \pm 0.04 \mathrm{mM}$ in rats injected with control Adv-lacZ or Adv-resistin, respectively $(P<0.01)$. The differences in FFA suppression between rats injected with Adv-lacZ or Adv-resistin, at each insulin infusion rate, are summarized in Figure 4B. These results are consistent with decreased adipose tissue insulin sensitivity in the hyper-resistinemic animals.

Insulin signaling studies. To explore the potential cellular mechanisms involved in the chronic resistin-induced decrease in insulin sensitivity, we obtained skeletal muscle, epididymal adipose tissue, and liver samples at the end of the maximal euglycemichyperinsulinemic clamping study. These samples, which represent the fully "insulinized" state at the termination of the glucose clamp study, were homogenized, fractionated by SDS-PAGE, and subjected to immunoblotting.

We first determined whether resistin interferes with the activation of upstream insulin-signaling components by measuring IR, IRS-1, and IRS-2 protein levels and phosphorylation status in skeletal muscle, adipose tissue, and liver samples. Chronic hyper-resistinemia did not alter the extent of IR tyrosine phosphorylation or IR protein levels in response to insulin in any of the three tissue types (data not shown). In contrast, as seen in Figure 5, in skeletal muscle and adipose tissue, the levels of IRS-1 phosphorylation and protein content were decreased in rats injected with Advresistin. IRS-1 phosphorylation was decreased by $65 \%$ and $48 \%$

\section{Figure 4}

Plasma FFA concentrations in the basal state and during the euglycemic-hyperinsulinemic clamping study. (A) Plasma FFA in the basal state and during the hyperinsulinemic clamping study (insulin infusion rates, 4 and $25 \mathrm{mU} / \mathrm{kg} / \mathrm{min}$ ) in rats injected with AdvlacZ (white bars; $n=7$ and 10, respectively) or Adv-resistin (black bars, $n=7$ and 10, respectively). (B) Quantification of the percent difference in the suppression of circulating FFA levels during the hyperinsulinemic clamps at insulin infusion rates of 4 and $25 \mathrm{mU} / \mathrm{kg} /$ min in rats injected with Adv-resistin compared with rats injected with Adv-lacZ. ${ }^{*} P<0.01 ;{ }^{* *} P<0.05$ versus rats injected with Adv-lacZ.
$(P<0.01)$, while IRS-1 protein content was decreased by $59 \%$ and $28 \%$ $(P<0.01)$ in skeletal muscle and adipose tissue, respectively. IRS-2 phosphorylation was decreased by $62 \%$ and $34 \%(P<0.01)$, while IRS-2 protein content was decreased by $27 \%$ and $28 \%(P<0.05)$ in skeletal muscle and adipose tissue, respectively. In liver, IRS-1 phosphorylation and protein levels were unaffected by resistin overexpression, whereas IRS-2 phosphorylation and protein levels were decreased by $59 \%$ and $32 \%(P<0.01)$, respectively. These results show that the chronic hyper-resistinemic state is associated with decreased signaling in skeletal muscle and adipose tissue via the IR-IRS-1-coupled pathway due to downregulation of IRS-1 content and activity, and with decreased IR-IRS-2-coupled signaling in the liver due to diminished IRS- 2 content and activity.

We also measured Akt phosphorylation at Ser473 and Thr308 in skeletal muscle, adipose tissue, and liver samples obtained from rats in the basal state and at the end of the maximal euglycemichyperinsulinemic experiments. As shown in Figure 6, insulin led to a marked stimulation of Akt phosphorylation in skeletal muscle, adipose tissue, and liver from rats injected with Adv-lacZ. This effect of Akt phosphorylation at Ser473 and Thr308 was blunted by $40-60 \%(P<0.01)$ in skeletal muscle, adipose tissue, and liver of the rats injected with Adv-resistin.

Resistin causes defective AMPK activation in response to insulin. Since AMPK signaling affects insulin-sensitive glucose metabolism (19-22) and since AMPK can act upstream of Akt signaling (23, 24), we assessed whether resistin overexpression alters AMPK activity. As demonstrated in Figure 7, AMPK phosphorylation (Thr172) was reduced by $60 \%, 35 \%$, and $64 \%(P<0.01)$ in the
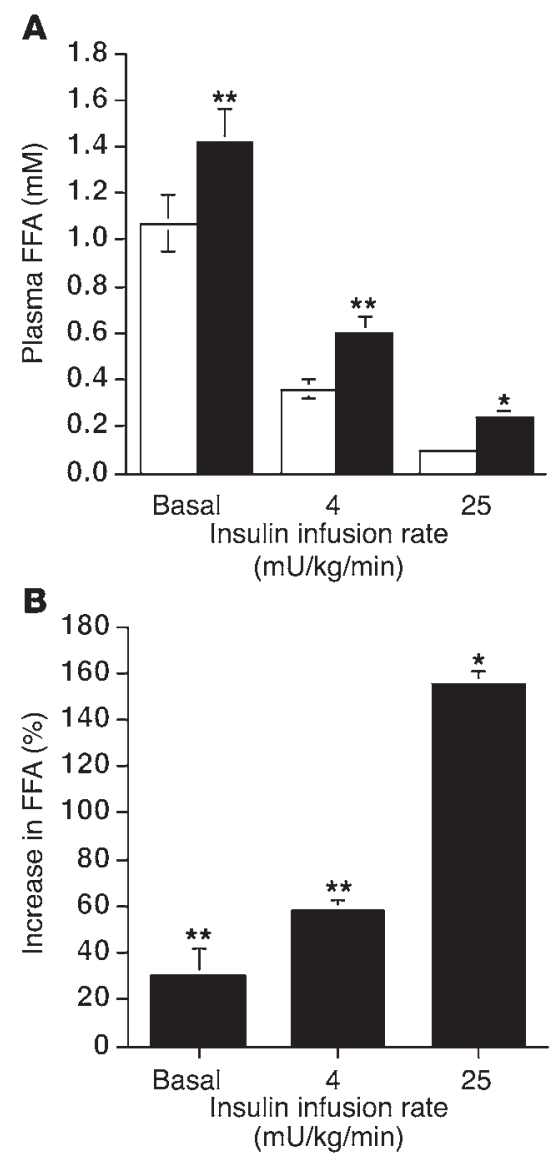

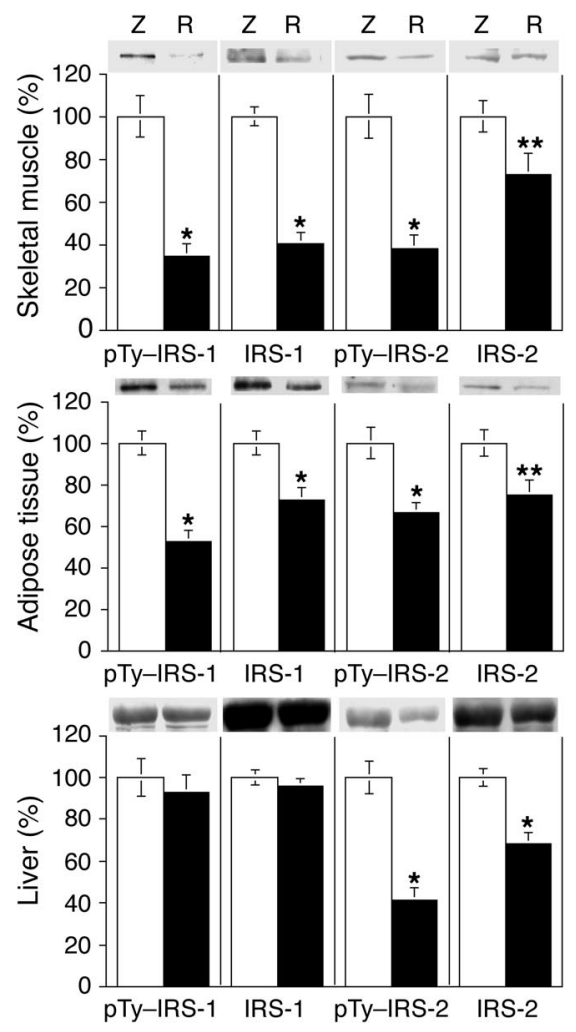

skeletal muscle, adipose tissue, and liver of rats injected with Adv-resistin, respectively, while AMPK protein content remained unchanged. Interestingly, it has been previously reported that leptin and adiponectin can stimulate $\operatorname{AMPK}(19,22)$. However, in the rats injected with Adv-resistin, the inhibition of AMPK activation appeared to be independent of adiponectin or leptin levels, as the levels of these two adipokines were not altered by hyperresistinemia (leptin: Adv-resistin, $7.03 \pm 2.56 \mathrm{ng} / \mathrm{ml}$; Adv-lacZ, $7.74 \pm 3.12 \mathrm{ng} / \mathrm{ml}$; adiponectin: Adv-resistin, $8.66 \pm 1.1 \mu \mathrm{l} / \mathrm{ml}$; AdvlacZ, $7.94 \pm 2.30 \mu \mathrm{l} / \mathrm{ml}$; Table 1$)$.

\section{Discussion}

Resistin is a recently described, adipocyte-secreted polypeptide (adipokine) that is upregulated in obese states (9) and is capable of causing decreased whole-body insulin sensitivity (9). To further explore the effects of elevated circulating resistin levels on insulin sensitivity, we have developed an animal model of hyperresistinemia by using in vivo Adv gene transfer to express wild-

\section{Figure 6}

Effect of resistin on Akt phosphorylation in skeletal muscle, liver, and adipose tissue. Basal and insulin clamp-stimulated skeletal muscle, adipose tissue, and liver samples were obtained and homogenized as described in Methods. After fractionation of the resulting homogenates $(50 \mu \mathrm{g})$ by $10 \%$ SDS-PAGE, proteins were transferred onto PVDF membranes. Membranes were probed with phosphorylated Akt (pAkt) (Ser473 and Thr308) and Akt antibodies. The bar graphs show data quantification by $\mathrm{NIH}$ Image for results in skeletal muscle, adipose tissue, and liver. Values are means \pm SEM of three independent experiments using six animals for each group. Data are expressed relative to control Adv-lacZ values, with a value of $100 \%$ assigned to the insulinstimulated control mean. ${ }^{*} P<0.01$.

\section{Figure 5}

Effect of resistin on tyrosine phosphorylation of IRS-1 (pTy-IRS-1) and IRS-2 (pTy-IRS-2) in skeletal muscle, liver, and adipose tissue. Insulin-stimulated skeletal muscle, adipose tissue, and liver samples were obtained at the end of the hyperinsulinemic clamp study and were homogenized. The resulting homogenates $(1 \mathrm{mg})$ were immunoprecipitated with polyclonal antibodies directed against IRS-1 or IRS-2, followed by separation of the immunoprecipitated proteins by SDS-PAGE and transfer onto PVDF membrane. Membranes were probed with anti-phosphotyrosine, anti-IRS-1, and anti-IRS-2. The bar graphs show data quantification by NIH Image for results in skeletal muscle, adipose tissue, and liver. Values are means \pm SEM of three independent experiments using six animals for each group. They are expressed relative to control Adv-lacZ values, which were set at $100 \%$. ${ }^{*} P<0.01 ;{ }^{* *} P<0.05$. White bars and $Z$, rats injected with Adv-lacZ; black bars and $\mathrm{R}$, rats injected with Adv-resistin.

type resistin in liver. With this approach, mouse resistin cDNA was cloned into an Adv vector and Adv-resistin was administered intravenously to male Wistar rats. Adv-resistin was targeted to the liver and more than $90 \%$ of hepatocytes were infected. In turn, the liver cells secreted resistin into the circulation, creating a chronic hyper-resistinemic state. The major finding of this study is that chronic hyper-resistinemia leads to glucose intolerance and postprandial hyperinsulinemia associated with decreased insulin sensitivity in skeletal muscle, liver, and adipose tissue. These animals
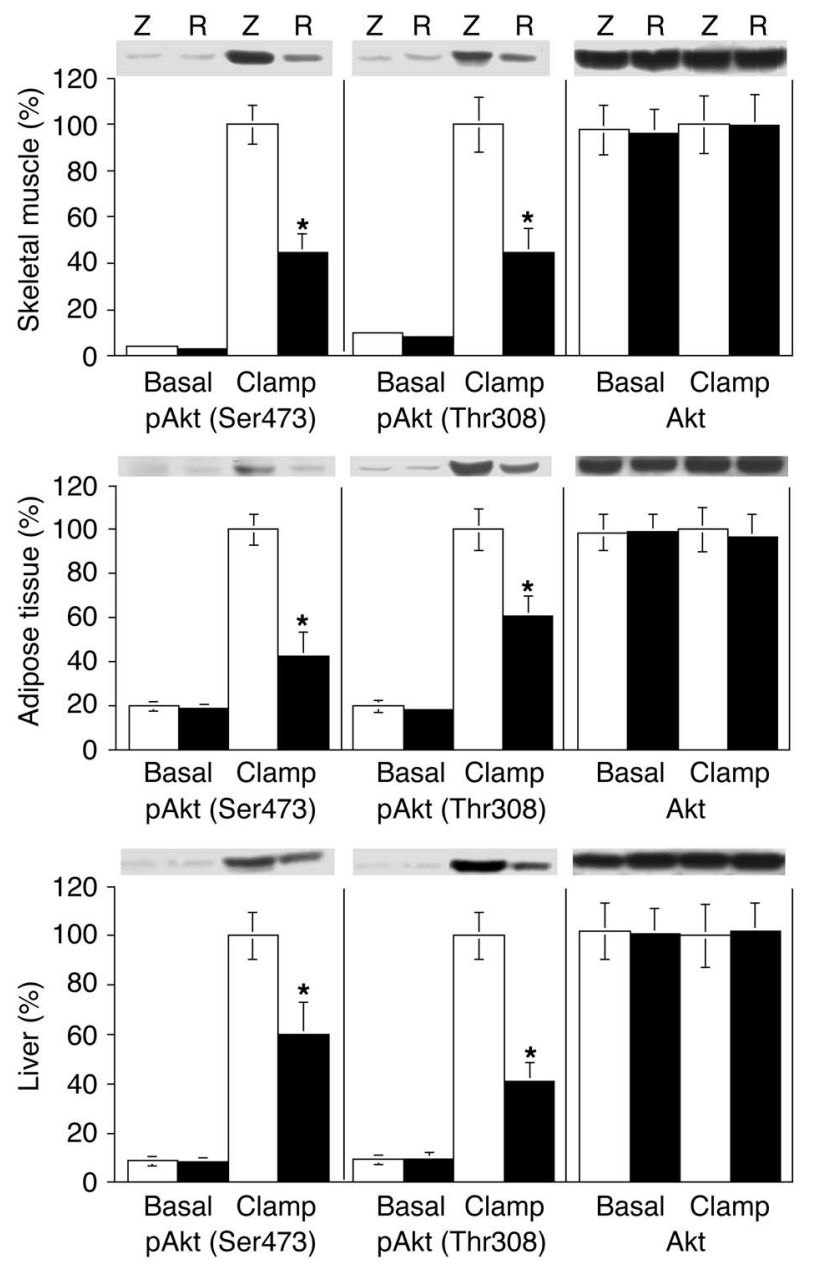

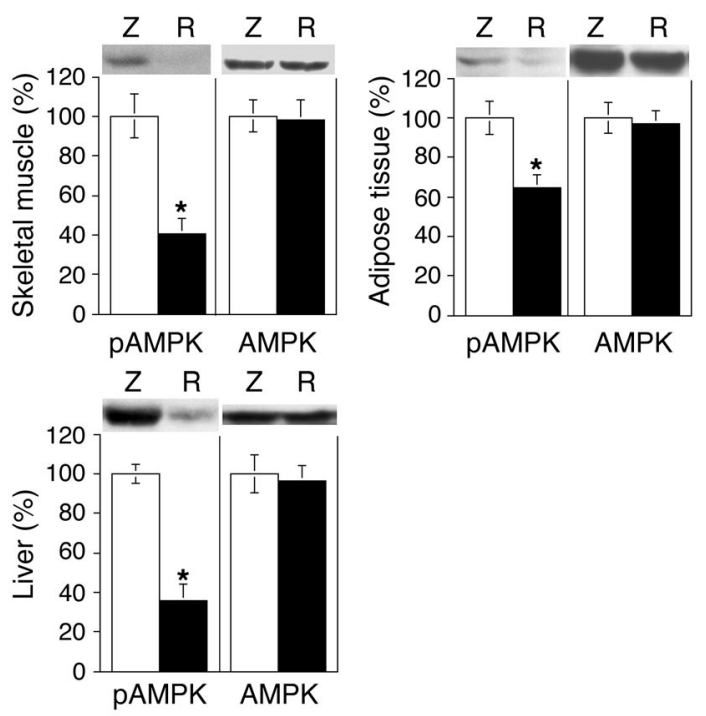

\section{Figure 7}

Decreased AMPK phosphorylation in skeletal muscle, liver, and adipose tissue of hyper-resistinemic rats. Insulin clamp-stimulated skeletal muscle, adipose tissue, and liver samples were collected and homogenized as described in Methods. After fractionation of the resulting homogenates $(50 \mu \mathrm{g})$ by $10 \%$ SDS-PAGE, proteins were transferred to PVDF membranes. Membranes were probed with phosphoryolated AMPK (pAMPK) (Thr172) and AMPK antibodies. The bar graphs show data quantification by NIH Image for results in skeletal muscle, adipose tissue, and liver. Values are means \pm SEM of three independent experiments using six animals for each group. Data are expressed relative to control Adv-lacZ values, which were set at $100 \% .{ }^{*} P<0.01$.

also display other features of the insulin resistance syndrome such as hypertriglyceridemia and elevated FFA levels, indicating that hyper-resistinemia can reproduce many of the central components of human syndrome X.

These data show that chronic hyper-resistinemia leads to totalbody insulin resistance that is manifested by decreased insulin sensitivity in all three of the major insulin target tissues: muscle, liver, and fat. These studies do not definitively show whether the decreased insulin sensitivity in these tissues occurs due to direct effects of resistin on all three tissues or whether the primary effects of resistin are exerted in one tissue with cross-talk or some other mechanism, leading to secondary insulin resistance in the other tissues. Recently, we have shown that in animals lacking PPAR $\gamma$ in muscle, primary insulin resistance in muscle can lead to secondary insulin resistance in liver and adipose tissue (25), and other examples of tissue cross-talk in which primary insulin resistance in one tissue leads to decreased insulin sensitivity in other tissues also exist (26). Therefore, our studies do not rule out the possibility that the initial effects of resistin are exerted in one insulin target tissue, with secondary changes appearing in others. Rajala et al. (14) have previously shown that acute intravenous administration of resistin led to marked hepatic insulin resistance but did not impair insulin-stimulated GDR. However, this study was conducted after only 30-90 minutes of resistin administration, and therefore it is possible that chronic hyperresistinemia, as in our current study, leads directly to additional effects in muscle and fat. One could speculate that the initial effects of resistin in causing decrease insulin sensitivity take place in the liver and that in the context of the whole animal, this results in hyperinsulinemia and elevated FFA levels, and that these, in turn, lead to secondary insulin resistance in other tissues. On the other hand, in vitro studies show direct effects of resistin to decrease insulin action in muscle (15) and fat tissue (9), and acute in vivo administration of resistin causes hepatic insulin resistance (14). Thus, it seems likely that this adipokine can also exert direct effects in vivo in all three tissues. However, once this insulin-resistant state is initiated, it is obvious that secondary changes related to hyperinsulinemia, increased circulating FFA levels, or other factors will subsequently develop.

Moreover, the cellular measurements shed light on potential mechanisms of action of resistin that indicate involvement of AMPK. AMPK is a heterotrimeric protein consisting of a catalytic subunit $(\alpha)$ and two noncatalytic subunits ( $\beta$ and $\gamma$ ) (27-29), whose activity is regulated via protein-protein interactions, allosteric interactions, and phosphorylation/dephosphorylation at a major activating site (Thr172) located in the $\alpha$-catalytic subunit (27-29). AMPK activation promotes translocation of GLUT4 to the plasma membrane, thus stimulating glucose uptake (19-22, 30), and AMPK can function upstream of Akt, at least in endothelial cells $(23,24)$. We found a uniform decrease in AMPK activity as measured by AMPK phosphorylation, in liver, muscle, and fat. This is unlikely to be a generalized manifestation of secondary insulin resistance, as decreased AMPK phosphorylation has not been reported as a common feature of insulin-resistant states $(31,32)$. This raises the possibility that resistin directly decreases AMPK activity, and to our knowledge there are no published direct in vitro studies that address this question. Interestingly, however, it is known that both leptin and adiponectin can increase AMPK activity, but as leptin and adiponectin levels were comparable between the rats injected with Adv-resistin and those injected with $\mathrm{Adv}-\mathrm{lacZ}$, and as resistin is an adipokine that generally has effects opposite to those of leptin and adiponectin, it is likely that resistin decreases AMPK activity. It is possible that hyper-resistinemia exerts its primary effects on the liver by decreasing AMPK activity with attenuation of insulin's suppressive effects on HGO and, in the context of the whole organism, this could result in secondary muscle and adipose tissue insulin resistance.

We also found that IRS-1 protein levels and IRS-1 phosphorylation states were decreased in fat and muscle from hyper-resistinemic animals and that IRS-2 protein levels and IRS-2 phosphorylation states as well as Akt activity were markedly decreased in all three tissues. Because the in vitro studies showing that resistin leads directly to insulin resistance in cultured muscle cells demonstrated no resistin-induced defect in IRS-1, PI3 kinase, or Akt activity (15), it seems most likely that the defects in IRS-1, IRS-2, and Akt that we observed are secondary manifestations of insulin resistance possibly due to the hyperinsulinemia, the elevated circulating FFA levels, or some other factor. Indeed, it is already established that elevated insulin levels, and/or FFA levels, can lead to these kinds of signaling defects (33).

In conclusion, we have shown that chronic hyper-resistinemia leads to hepatic insulin resistance as well as whole-body insulin resistance, including skeletal muscle and adipose tissue. The mechanism whereby resistin decreases insulin sensitivity involves a reduction in AMPK activity in skeletal muscle, adipose tissue, and liver and of IRS- 1 in adipose tissue and skeletal muscle. These decreases in tissue insulin sensitivity result in glucose intolerance, 
hyperinsulinemia, elevated FFA levels, and hypertriglyceridemia, all of which are major features of human syndrome X. Obviously, the precise role resistin may play in human pathophysiological states will depend on the results of future studies measuring resistin levels and the effects of treatment of these conditions.

\section{Acknowledgments}

We are indebted to Elizabeth Hansen for editorial assistance. This work was supported in part by NIH grant DK-33651 and a grant from The Larry L. Hillblom Foundation.

1. Shulman, G.I. 2000. Cellular mechanisms of insulin resistance. J. Clin. Invest. 106:171-176.

2. Olefsky, J.M., and Saltiel, A.R. 2000. PPAR gamma and the treatment of insulin resistance. Trends Endocrinol. Metab. 11:362-368.

3. Olefsky, J.M. 2000. Treatment of insulin resistance with peroxisome proliferator-activated receptor gamma agonists. J. Clin. Invest. 106:467-472.

4. Hotamisligil, G.S., Shargill, N.S., and Spiegelman, B.M. 1993. Adipose expression of tumor necrosis factor-alpha: direct role in obesity-linked insulin resistance. Science. 259:87-91.

5. Zhang, Y., et al. 1994. Positional cloning of the mouse obese gene and its human homologue. Nature. 372:425-432.

6. Hu, E., Liang, P., and Spiegelman, B.M. 1996. AdipoQ is a novel adipose-specific gene dysregulated in obesity. J. Biol. Chem. 271:10697-10703.

7. Maeda, K., et al. 1996. cDNA cloning and expression of a novel adipose specific collagen-like factor, apM1 (AdiPose Most abundant Gene transcript 1). Biochem. Biophys. Res. Commun. 221:286-289.

8. Scherer, P.E., Williams, S., Fogliano, M., Baldini, G., and Lodish, H.F. 1995. A novel serum protein similar to C1q, produced exclusively in adipocytes. J. Biol. Chem. 270:26746-26749.

9. Steppan, C.M., et al. 2001. The hormone resistin links obesity to diabetes. Nature. 409:307-312.

10. Steppan, C.M., et al. 2001. A family of tissue-specific resistin-like molecules. Proc. Natl. Acad. Sci. U. S. A. 98:502-506.

11. Way, J.M., et al. 2001. Adipose tissue resistin expression is severely suppressed in obesity and stimulated by peroxisome proliferator-activated receptor gamma agonists. J. Biol. Chem. 276:25651-25653.

12. Yang, R.Z., et al. 2003. Comparative studies of resistin expression and phylogenomics in human and mouse. Biochem. Biophys. Res. Commun. 310:927-935.

13. Nagaev, I., and Smith, U. 2001. Insulin resistance and type 2 diabetes are not related to resistin

Received for publication December 11, 2003, and accepted in revised form April 14, 2004.

Address correspondence to: Jerrold M. Olefsky, Department of Medicine, University of California, San Diego, 9500 Gilman Drive, La Jolla, California 92093-0673, USA. Phone: (858) 534-6651; Fax: (858) 534-6653; E-mail: jolefsky@ucsd.edu.

Hiroaki Satoh and M.T. Audrey Nguyen contributed equally to this work.

expression in human fat cells or skeletal muscle. Biochem. Biophys. Res. Commun. 285:561-564.

14. Rajala, M.W., Obici, S., Scherer, P.E., and Rossetti, L. 2003. Adipose-derived resistin and gut-derived resistin-like molecule- $\beta$ selectively impair insulin action on glucose production. J. Clin. Invest. 111:225-230. doi:10.1172/JCI200316521.

15. Moon, B., Kwan, J.J., Duddy, N., Sweeney, G., and Begum, N. 2003. Resistin inhibits glucose uptake in L6 cells independently of changes in insulin signaling and GLUT4 translocation. Am. J. Physiol. Endocrinol. Metab. 285:E106-E115.

16. Steele, R. 1959. Influences of glucose loading and of injected insulin on hepatic glucose output. Ann. N. Y. Acad. Sci. 82:420-430.

17. Herz, J., and Gerard, R.D. 1993. Adenovirus-mediated transfer of low density lipoprotein receptor gene acutely accelerates cholesterol clearance in normal mice. Proc. Natl. Acad. Sci. U. S. A. 90:2812-2816

18. Wilson, J.M. 1996. Adenoviruses as gene-delivery vehicles. N. Engl. J. Med. 334:1185-1187.

19. Yamauchi, T., et al. 2002. Adiponectin stimulates glucose utilization and fatty-acid oxidation by activating AMP-activated protein kinase. Nat. Med. 8:1288-1295.

20. Fryer, L.G., et al. 2000. Activation of glucose transport by AMP-activated protein kinase via stimulation of nitric oxide synthase. Diabetes. 49:1978-1985.

21. Hayashi, T., Hirshman, M.F., Kurth, E.J., Winder, W.W., and Goodyear, L.J. 1998. Evidence for 5' AMP-activated protein kinase mediation of the effect of muscle contraction on glucose transport. Diabetes. 47:1369-1373.

22. Minokoshi, Y., et al. 2002. Leptin stimulates fattyacid oxidation by activating AMP-activated protein kinase. Nature. 415:339-343.

23. Nagata, D., Mogi, M., and Walsh, K. 2003. AMPactivated protein kinase (AMPK) signaling in endothelial cells is essential for angiogenesis in response to hypoxic stress. J. Biol. Chem.
278:31000-31006.

24. Chen, H., Montagnani, M., Funahashi, T., Shimomura, I., and Quon, M.J. 2003. Adiponectin stimulates production of nitric oxide in vascular endothelial cells. J. Biol. Chem. 278:45021-45026.

25. Hevener, A.L., et al. 2003. Muscle-specific Pparg deletion causes insulin resistance. Nat. Med. 9:1491-1497.

26. Wilkes, J.J., Hevener, A., and Olefsky, J. 2003. Chronic endothelin-1 treatment leads to insulin resistance in vivo. Diabetes. 52:1904-1909.

27. Woods, A., et al. 1996. Characterization of AMPactivated protein kinase beta and gamma subunits. Assembly of the heterotrimeric complex in vitro. J. Biol. Chem. 271:10282-10290.

28. Stapleton, D., et al. 1996. Mammalian AMPactivated protein kinase subfamily. J. Biol. Chem. 271:611-614.

29. Hawley, S.A., et al. 1995. 5'-AMP activates the AMP-activated protein kinase cascade, and $\mathrm{Ca} 2+$ / calmodulin activates the calmodulin-dependent protein kinase I cascade, via three independent mechanisms. J. Biol. Chem. 270:27186-27191.

30. Lemieux, K., Konrad, D., Klip, A., and Marette, A. 2003. The AMP-activated protein kinase activator AICAR does not induce GLUT4 translocation to transverse tubules but stimulates glucose uptake and p38 mitogen-activated protein kinases alpha and beta in skeletal muscle. FASEB J. 17:1658-1665.

31. Bergeron, R., et al. 2001. Effect of 5-aminoimidazole-4-carboxamide-1-b-D-ribofuranoside infusion on in vivo glucose and lipid metabolism in lean and obese Zucker rats. Diabetes. 50:1076-1082.

32. Olsen, G.S., and Hansen, B.F. 2002. AMP kinase activation ameliorates insulin resistance induced by free fatty acids in rat skeletal muscle. Am. J. Physiol. Endocrinol. Metab. 283:E965-E970.

33. Hevener, A.L., Reichart, D., Janez, A., and Olefsky, J. 2001. Thiazolidinedione treatment prevents free fatty acid-induced insulin resistance in male wistar rats. Diabetes. 50:2316-2322. 